\title{
EPISTEMOLOGIA NATURALIZADA E PSICANÁLISE: UM HORIZONTE DE EXPECTATIVA
}

\section{Naturalized Epistemology and Psychoanalysis: an expectation horizon}

\author{
Maria Cristina de Távora Sparano ${ }^{1}$ \\ Silvia Maria Monteiro \\ Patrícia Pereira ${ }^{2}$
}

Resumo

A tese do holismo semântico de Quine apresenta-se como uma proposta interessantena formulação do quadro epistemológico dapsicanálise. Emesmo afirmando-se que a psicanálise não é uma ciência no sentido estrito, pode-se dizer que é uma conseqüência do discurso científico, que supõe uma dimensão lógica a ordenar este discurso, com todo o aparato conceitual e doutrinal de uma ciência. A tese holista quiniana tem papel fundamental na epistemologia do século XX, caractenzando-se como pós-positivista e antivenificacionista. Quine já apresenta seus pressupostos teónicos no texto "Dois dogmas do empirismo" onde critica a distinção entre verdades analíticas e verdades sintéticas. A revisão do sentido da analiticidade é a versão quiniana de que as observações sempre estão "carregadas de teoria" e sua resposta virá na forma do holismo semântico. O reducionismo radical é o segundo dogma criticado por Quine e sua conclusão é que não é possível verificar cada proposição sobre o mundo físico de maneira isolada. A epistemologia quiniana, de acordo com a perspectiva holística, está além da tarefa de descrever a natureza, sua epistemologia está na natureza. Em psicanálise, autocomeção e inovação no curso da interpretação dos casos clínicos, apresentam-na como um corpus teórico orgânico afinada com o holismo quiniano.

Palavras-chave: Holismo semântico; Epistemologianaturalizada; Psicanálise.

1 Grupo de Estudos da Linguagem da Universidade Federal do Paraná. Universidade Federal do Paraná, Pós-Graduação em Psicologia. Praça Santos Andrade, 50 Centro 80020-300 - Curitiba, PR - Brasil - Telefone: (41) 3310-2644 Fax: (41) 3310-2644 E-mail: sparano@ufpr.br

2 URL da Homepage: http://www.humanas.ufpr.br

Revista de Filosofia, Curitiba, v. 17 n.20, p. 125-136, jan./jun. 2005. 


\section{Abstract}

The theory of semantic holism of Quine comes as an interesting proposal in the formulation of the epistemological set of the psychoanalysis. And even being affirmed that the psychoanalysis is not a science in the strict sense, it can be said that it is a consequence of the scientific speech, that it supposes a logical dimension to order this speech, with the whole conceptual and doctrinal apparatus of a science. Quine's holist theory has fundamental paper in the epistemology of the century XX, being characterized as pos-positivists and anti-verificationist. Quine already presents his theoretical presuppositions in the article "Two dogmas of the empiricism" where it criticizes the distinction between analytical truths and synthetic truths. The revision of the notion of analyticity is the quinean version that observations are always "loaded of theory" and his answer will come in the form of the semantic holism.The radical reductionism is the second dogma criticized by Quine and his conclusion is that it is not possible to verify each proposition on the physical world in an isolated way. Quine's epistemology, in agreement with the holistical perspective, is besides the task of describing the nature, his epistemology is in the nature. In psychoanalysis, autocorrection and innovation in the course of the interpretation of the clinical cases introduce psychoanalysis as a theoretical organic corpus tuned with the Quinean Holism.

Keywords: Semantic Holism; Naturalized Epistemology; Psychoanalysis.

\section{Introdução}

Se a epistemologia é, para Quine, a teoria do método e da evidência e a ontologia é uma teoria sobre o que há, será o empirismo a preferida e mais coerente teoria do método e da evidência e, por sua vez, a ciência natural a única evidência para uma teoria do que existe. Nossa única evidência é a evidência sensível. O naturalismo é a pedra de toque da filosofia quiniana, mas supõe uma construção progressiva, pois todo conhecimento será passível de revisão. É com esse "framework", onde epistemologia contém ontologia e vice-versa, que Quine fornece uma justificação para o nosso conhecimento do mundo externo, inseparável de uma teoria psicológica de estímulo e resposta aplicada à linguagem.

O projeto epistemológico de Quine tem como finalidade a compreensão da ciência. Seu projeto é empirista, mas trata os resultados cien-

Revista de Filosofia, Curitiba, v. 17 n.20, p. 125-136, jan./jun. 2005. 
tíficos no interior das ciências constituídas. Quine afirma que não há base mais firme para uma reflexão sobre a ciência do que ela mesma e que somos livres para utilizar os resultados de uma ciência quando investigamos suas "raízes". A essa epistemologia não fundacional reintegrada às ciências da natureza dá-se o nome de epistemologia naturalizada.

Objeto físico num mundo físico - A reflexão sobre os fundamentos da ciência comporta:

a) pesquisas conceituais - que buscam esclarecer o significado dos conceitos, definindo uns a partir dos outros, os mais obscuros em função dos mais claros, em busca da maior clareza possível, e;

b) pesquisas doutrinais - que visam a estabelecer leis, demonstrando umas a partir de outras, as menos evidentes sendo demonstradas a partir das mais evidentes, em busca de otimizar a certeza.

Para Quine, a pesquisa conceitual avança a partir da tradição semântica explicitada por Frege (1978) e ampliada por Russell (1978), com a Teoria das Descrições, admitindo-se que a unidade de significado é o enunciado, já que só dele, e não de suas partes, cabe perguntar pelo valor de verdade. Chegando-se com a Tese Duhen/Quine ${ }^{3}$ à admissão de que é a partir do todo da ciência que se decide se um enunciado qualquer é verdadeiro ou falso. No aspecto doutrinal, Quine acrescenta:

Não vejo que estejamos hoje mais avançados do que na época de Hume. O impasse humeano é o impasse humano.(...) A mais modesta generalização sobre os dados observáveis encerra muito mais casos que aquele que quem profere tal enunciado pôde ter a ocasião de observar. É preciso reconhecer que não há esperança de poder fundamentar, por via claramente lógica, a ciência da natureza sem a experiência imediata. (...) (QUINE, 1980).

3 Partindo dos pressupostos de que as teorias físicas transcendem todas as observações possíveis do mundo; e que teorias diversas e conflitantes podem apoiar-se nos mesmos dados da observação, Pierre Duhen chega à tese de que É possível construir teorias logicamente incompatíveis e empiricamente equivalentes. Quine, ampliando a tese, diz que todos os nossos enunciados confrontariam o tribunal da experiência apenas em bloco. Diante de um experimento ou experiência recalcitrante, nenhum enunciado teria o seu valor de verdade imune à revisão, pois sempre poderíamos fixálo se revisássemos o valor de verdade dos outros enunciados. Desta tese podemos inferir que as condições de confirmação do valor de verdade de um enunciado não podem ser determinadas isoladamente pelas evidências, mas dependem do papel que estes enunciados desempenham na teoria a qual pertence.

Revista de Filosofia, Curitiba, v. 17 n.20, p. 125-136, jan./jun. 2005. 
Ou seja, Quine mantém do empirismo a idéia de que toda prova científica é de ordem sensorial e que o significado lingüístico tem de ter apoio em dados sensíveis, e sugere que a epistemologia se naturalize e se torne uma ciência natural, que trata de um fenômeno natural: o homem.

Eu sou um objeto físico num mundo físico. Raios luminosos atingem minhas retinas; moléculas bombardeiam meus ouvidos e pontas dos dedos. Eu respondo emanando ondas de ar concêntricas. Estas ondas tomam a forma de uma torrente de discurso sobre mesas, pessoas, moléculas, (...) classes infinitas, alegria e tristeza, bom e mau.

A minha capacidade para responder desta forma elaborada consiste em eu ter assimilado uma boa parte da cultura da minha comunidade, possivelmente modificando-a e elaborando-a um pouco por minha conta. Todo este treino consistiu por sua vez num embate de forças físicas, majoritariamente elocuções de outras pessoas, na minha superfície, e em mudanças graduais na minha própria constituição em conseqüência destas forças físicas. Tudo o que sou ou que espero vir a ser devese às irritações da minha superfície (...) E todo o saber dos tempos é devido à irritação das superfícies de uma sucessão de pessoas, juntamente, de novo, com as condições internas iniciais desse vários indivíduos (QUINE, 1995).

O alcance da linguagem da ciência - Para Quine, cabe à análise da linguagem identificar e compreender as variáveis que interagem no comportamento dos falantes e como se dá a determinação de uma resposta, ou, a constituição anatômica de um significado. A análise da linguagem deve apoiar-se na observação do comportamento dos falantes. Seu naturalismo epistemológico é expresso na convicção de que as teorias sobre a linguagem são passíveis de verificação empírica, uma vez que tratam de fenômenos naturais e observáveis: o discurso, os atos lingüísticos, as respostas que este provoca em seus ouvintes, os processos de aquisição da linguagem.

Estímulo e resposta são categorias associadas ao meio social e ao comportamento dos indivíduos, ambas devem estar intimamente inter-relacionadas. Quine dá como exemplo da inter-relação a aquisição da palavra por uma criança, quando a criança enunciar "vermelho", é 
porque terá sido instigada por estimulação a enfatizar a cor do objeto. Do ponto de vista behaviorista, espera-se que a criança adquira um comportamento verbal por meio da observação, da imitação de adultos, das outras crianças e por meio da manipulação dos dados externos. Supõese que o dispositivo mental da criança possui determinados mecanismos analíticos de processamento de dados ou princípios indutivos elementares, como os princípios de associação, os princípios de generalização e os princípios taxonômicos de segmentação e de classificação. Na interrelação dá-se a constituição anatômica do significado.

A língua é vista como uma coleção de palavras, locuções e sentenças; um sistema cujos hábitos são adquiridos e explicados pelo meio externo. A aquisição da linguagem, a formulação de conceitos, e nosso conhecimento seria o resultado de uma construção gradativa que ocorre primordialmente pela experiência. Quine (1980) diz, no artigo Relatividade Ontológica: "A linguagem é uma arte social que nós todos adquirimos em circunstâncias publicamente reconhecíveis (...)"; mais adiante, corrobora a noção de Dewey de que "o significado não é uma existência psíquica; é antes uma propriedade do comportamento" (QUI$\mathrm{NE}, 1969)$.

O fato de o significado ser constituído, na perspectiva naturalista, de um modo anatômico - e socialmente anatômico - é determinante na compreensão da intersubjetividade como fundamental no critério de decidibilidade entre teorias, bem como no processo de aquisição de significado dos predicados da ciência.

Ciência em desenvolvimento - Longe de pretender uma reconstrução lógica do mundo exterior a partir de dados sensíveis, caberá à ciência explicar como esse "objeto físico" quiniano, a partir de estimulações controláveis experimentalmente, produz outro objeto físico, seu discurso.

Como as teorias superam o nível dos dados da experiência sensível? Quine (1995) alude a dois aspectos de uma teoria: sua ontologia que consiste na decisão sobre o domínio da quantificação, ou seja, o procedimento de ligação das variáveis do discurso de modo a determinar, no discurso, o escopo de um quantificador existencial ou universal; e sua ideologia - as idéias que são exprimíveis na linguagem da teoria. Mas ontologia de uma teoria não está em correspondência simples com sua ideologia. A ideologia de uma teoria não exaure o escopo de sua

Revista de Filosofia, Curitiba, v. 17 n.20, p. 125-136, jan./jun. 2005. 
ontologia. Duas teorias podem ter a mesma ontologia e diferentes ideologias. A base mais sólida para nosso conhecimento e nosso discurso são os "objetos físicos"

(...) a ciência é uma continuação do senso comum, e ela continua a utilizar o recurso do senso comum de expandir a ontologia para simplificar a teoria (...) Objetos físicos são introduzidos conceitualmente como intermediários convenientes (...) comparáveis, epistemologicamente, aos deuses de Homero. (...) os objetos físicos e os deuses diferem apenas em grau, não em espécie (QUINE, 1980, p. 253).

Mas, afinal, quais os enunciados que "valem" para a ciência?

Se o predicado for para ser usado para a aplicação aos objetos macroscópicos do senso comum, então há uma utilidade óbvia em haver uma tendência geral para o acordo, entre os observadores, no que se refere à sua aplicação a esses objetos; porque é nessas aplicações que a verificabilidade intersubjetiva dos dados da ciência reside (QUINE, 1995, p. 40).

A postulação de objetos afastados da observação e do senso comum também visa a facilitar a compreensão dos fatos que se está tentando explicar. $\mathrm{O}$ processo de postulação de objetos físicos é semelhante ao dos postulados científicos, a diferença é de antiguidade e de nível de complexidade: (...) os predicados apropriados à ciência são aqueles que realizam com presteza

os propósitos de confirmação intersubjetiva, clareza e simplicidade teóricas (QUINE, 1995, p. 40).

Confirmação intersubjetiva, clareza e simplicidade governam a decisão ontológica. Uma decisão, sempre relativa ao corpo organizado de nossas teorias de mundo, apoiadas pelas comunidades científicas de cada época, mas que fornece os lastros para garantir a certeza sobre 0 valor-de-verdade dos enunciados que constituem, em conjunto, o todo deste sistema.

O discurso do senso comum e o discurso científico são teóricos, dependentes da teoria de mundo que lhes confere significado e valorde-verdade. Ambos postulam inobserváveis, dependem de fundamentos lógicos, lingüísticos e culturais. Nenhum de seus enunciados é significativo se isolado de seu contexto nem pode ser comparável, diretamente,

Revista de Filosofia, Curitiba, v. 17 n.20, p. 125-136, jan./jun. 2005. 
aos fatos que descreve. Nisto se fundamenta a tese da relatividade ontológica, salvaguardada do ceticismo pelo acordo consensual que leva em consideração além dos critérios já citados, também o estágio do desenvolvimento da ciência em nossa época.

Epistemologia naturalizada e psicanálise - Como pensar a psicanálise no seio de um projeto epistemológico atual como o de Quine? Tornou-se o modelo da psicanálise do séc. XIX, dividida entre ciência do espírito (Geistwissenchaft) e ciência da natureza (Naturwissenchaft) obsoleto? Que conjuntos de enunciados e que variáveis considerar para se pensar a psicanálise pelo prisma da epistemologia naturalizada?

A psicanálise é uma teoria, e o seu método - o da associação livre (que pela linguagem não descreve fenômenos, mas efeitos psicológicos) - ao transformar sensações em representações associadas tem como objetivo apenas uma coisa: fugir da dor e encontrar prazer. Entretanto a teoria, tão cara a Freud, não passará pelo teste de falseabilidade da ciência como postulou Popper, pois não encontrará uma instância falseadora que refute ou confirme a teoria. Por outro lado, considerando a sensação como unidade quantitativa mínima, Freud considera o acúmulo interno de sensações e a descarga dessas quantidades, um processo em relação ao mundo, cuja expressão toma caminhos diversos, mas confere ao princípio do prazer a força de uma lei: o ser humano natural (objeto físico natural quiniano) busca satisfação e evita a dor. Podemos dizer que 0 programa da psicanálise é o programa do princípio do prazer. O Lustprincipiz é, para Freud, uma lei da qual nenhum fenômeno ou ser humano escapa: é a única evidência. Tomemos como ponto de partida 0 princípio do prazer, princípio que deve anular, ou ao menos evitar, as sensações de desprazer. Seu funcionamento nos diz que, dada uma certa quantidade de tensão (Q.T.), submetida ao circuito do princípio do prazer (P.P.), a quantidade deve, na descarga, ser reduzida a zero.

$$
\text { Q.T. }=\mathrm{x} \quad \text { P.P. Q.T. }=0
$$

Segundo Freud, como essa redução não ocorre, pois seria identificada em seu limite com a morte, na operação, resta sempre uma quantidade maior que zero que retornará ao organismo de outra forma, possivelmente como sintoma ou sublimação.

$$
\begin{aligned}
& \text { Q.T. }=\quad x>0 \\
& \text { P.R. (P.P.) }=\quad x>0
\end{aligned}
$$

Revista de Filosofia, Curitiba, v. 17 n.20, p. 125-136, jan./jun. 2005. 
Ocorre nesse ponto a introdução de um novo circuito, o do princípio da realidade (P.R.), com uma mesma finalidade, ou seja, a redução da Q.T. Modifica-se o programa, mas continua-se no princípio do prazer por outros meios.. Como diz J. A. Miller (1989): alguém dorme, mas como para dormir, encontra algumas dificuldades, abre os olhos e produz dados sobre o mundo, mas para continuar satisfazendo o princípio do prazer de tal maneira que como Lacan sugere, "abre os olhos para continuar dormindo".

A linguagem e o inconsciente -“...fechados os olhos se alucina, e a penas abertos se pensa em palavras" (FREUD, 1981).

Freud cria um campo novo, do inconsciente, como um campo de forças, onde as ações muitas vezes não encontram justificativas e são acessadas porque atualizadas pelos sonhos, sintomas, chistes ou atos falhos. O formalismo lingüístico foi imprescindível para sustentar os passos da linguagem, mas em Freud foi antecipado pelos tropeços dos passos da linguagem. A ordem dos fatos que Freud chama de inconsciente é isso: o sujeito diz, mas sem saber o que está dizendo. Expressão disso encontramos nas formações do inconsciente, nos sonhos ou de outra forma, quando o sujeito diz algo com a palavra que lhe falta, nos atos falhos ou quando as palavras faltam, o corpo diz ou fala pelos sintomas, por uma conduta singular ou anatômica. O fundamento desse processo não é fenomenológico, mas psicológico, está baseado em sensações que se transformam em representações associadas - palavras e proposições objeto da investigação psicanalítica que têm como expectativa buscar resposta para a questão da dor e do prazer.

Para Quine, a linguagem manifesta algo, mas é a "irritabilidade da superfície" que provoca a linguagem. $\mathrm{O}$ dispositivo conceitual tem a pretensão de controlar a excitabilidade que gera a linguagem, mas com a ressalva de que, é pela excitabilidade, do começo ao fim, é que podemos falar das coisas externas. O pensamento só pode ser concebido como uma associação complexa de representações cuja tarefa primordial é exprimir a realidade externa. Os relatos, ao descreverem a realidade, devem também comunicar algo constante que dê o caráter da realidade e temos assim a linguagem como índice do pensamento. No entanto, como a única forma de acesso ao pensamento é pelas palavras,os relatos do sujeito também pressupõem o pensar e temos então o pensamento como índice da linguagem.

Revista de Filosofia, Curitiba, v. 17 n.20, p. 125-136, jan./jun. 2005. 
Freud no cap. VII da Interpretação dos sonhos fala dos processos de derivação da excitação e expõe uma dinâmica desse funcionamento: "uma carga de energia é retirada de uma ordenação determinada de maneira que o produto psíquico fique situado sob o domínio de uma instância e subtraída a mesmo, o que parece dotado de movimento não é o produto mas sua enervação." Podemos concluir que as idéias ou as representações não são elementos orgânicos, mas se situam no nível de uma adequação de afeto que, segundo Freud, se apresenta deslocado e deformado mas, sobretudo, recalcado quando submetido à censura e cujo objetivo era evitar o desprazer. Como as representações sexuais são mais intensas que as sensações que as originam, elas são fatalmente condenadas a serem recalcadas, deslocadas e deformadas, mas não totalmente, restando sempre resíduos de representações que não foram totalmente censuradas. O sintoma pode ser considerado como um símbolo de afeto recalcado e deslocado, um representante instintual que submetido à censura retorna como símbolo de uma satisfação sexual há muito tempo recalcada (FREUD, 1960).

No sonho, a expressão é lingüística e a passagem à tradução do sonho pelo sonhador sempre deixa lacunas daquilo que é recalcado, ou seja, censurado. Por isso, o sonho não é aberto a inúmeros sentidos, mas possui um sentido original, submetido à condensação e deslocamento. Logo, toda interpretação é expressão desse afeto censurado. À pergunta de como fazer a passagem de um modelo natural a um modelo lingüístico ${ }^{4}$ encontra resposta na forma como o etnólogo quiniano passou das proposições observacionais às frases de seu manual de tradução, estabelecendo correlações hipotéticas que se transformam em hipóteses analíticas. O conjunto dessas hipóteses constitui o que se pode chamar um dicionário e uma gramática que o etnólogo aplica às frases e cuja tradução não repousa sobre nenhuma referência determinada. A interpretação dos sonhos percorre as cadeias associativas em que o material recente dos pensamentos do dia intercala-se nas séries nas quais o aumento de resistência levou a novos e mais distantes desvios. As hipóteses que o etnólogo é levado a formular são seus instrumentos de trabalho, assim como associação e interpretação no trabalho do sonho.

4 Conforme o texto Le mythe de la signification (1958/59) Colloque de Royamont, Paris, 1960.

Revista de Filosofia, Curitiba, v. 17 n.20, p. 125-136, jan./jun. 2005. 
A linguagem da ciência - Como justificar a proposição de um modelo para a psicanálise fundado numa perspectiva naturalista?

Freud diz no "Projeto..." que a observância das regras biológicas que governam o curso das séries de pensamentos protegem o processo do pensamento do desprazer intelectual da contradição e que é função do "eu" eliminar as contradições e que isso é lógico. Quando Quine, no texto “Dois dogmas do empirismo" rejeita a distinção entre componentes lingüísticos e componentes fáticos pretende com isso mostrar que o componente fático carrega teoria, mas que a teoria também é um produto do funcionamento da linguagem no mundo. A linguagem é social e a analiticidade também, já que suas verdades, fundadas na linguagem da lógica, "aprendemos" como verdadeiras.

No entanto, Quine afirma ainda que "em ciência tudo é provisório, tudo sujeito à revisão - inclusive a lei do terceiro excluído" (QUINE, 1995). Para que se justifique uma mudança no plano lógico, é necessária uma mudança de teoria e conseqüentemente do significado da linguagem. Isso determina o modo como aderimos à teoria. Por exemplo, quando deixamos de dizer que as baleias são peixes e passamos a considerá-las como mamíferos, mudou o significado da teoria ou a teoria? Assim como as hipóteses analíticas não admitem teste empírico, segundo o método do estímulo-significado esses enunciados são indecidíveis, o que não quer dizer que não tenham valor de verdade. Se a referência é inescrutável e conseqüentemente a adesão ontológica relativa, o que resta de invariável e sustenta a teoria é que todas as hipóteses são compatíveis com o comportamento racional observável dos falantes, logo há uma razão - guia que justifica o processo.

Os predicados utilizados em contextos mais afastados da observação, embora com maior dificuldade, devem estar livres de imprecisão. Quine irá dizer que a ideologia é menos estabelecida que a ontologia devido aos predicados admissíveis para a ciência. No entanto, a ontologia física associada à epistemologia naturalista pode, além dos objetos físicos, acolher os estados de espírito como se objetos físicos fossem. Pelos predicados utilizados, podemos identificar qualquer manifestação mental como identificamos o "hospedeiro" da manifestação durante todo o tempo de duração, como no caso de uma alucinação, do sonho ou um ataque de malária. Essa identificação graças ao paralelismo e extensionalidade da linguagem científica preserva a integridade dos idiomas mentalistas, como o idioma do sonho em psicanálise e os reconcilia com uma 
ontologia fisicalista. É a aceitabilidade dos predicados no lugar dos objetos que dá o valor das variáveis de quantificação. A melhor maneira de tratar a lógica é tratá-la como parte integrante da ciência, sob o mesmo plano da física, da economia onde há uma aplicação desses elementos. A psicanálise não estaria imune a essa possibilidade.

\section{Referências}

FREGE, G. Lógica e filosofia da linguagem. Tradução e notas de Paulo Alcoforado. São Paulo,SP: Cultrix. 1978.

FREUD S. Repressão. In: EDIÇÃO sta ndad brasileira das obras psicológicas completas de Sigmund Freud. Rio de Janeiro,Rj: Imago, 1974. (1915). v. 14. p.169-182.

. Proyeto de una psicologia para neurologos. Madrid: Biblioteca Nueva, 1981.

. La interpretacion de los sueños. Madrid: Biblioteca Nueva, 1981. cap. 7.

GABBI Jr., O. Freud: racionalidade, sentido e referência. Campinas: Editora da Unicamp, 1994. v. 13. p. 204.

LAKATOS, I.; MUSGRAVE, A. O Falseamento e a metodologia dos programas de pesquisa

científica. In:

A crítica e o desenvolvimento do conhecimento. São Paulo,SP: Cultrix, 1979.

MILIER, J. A. Conferência para docentes da Fac. de Psicologia. Buenos Aires: U. de Buenos Aires: Manacial, 1989.

POPPER, K. A Lógica da investigação científica. São Paulo, SP: Abril Cultural, 1980. p. 14-15. (Coleção Os Pensadores).

RUSSEL, B. lógica e conhecimento: ensaios escolhidos São Paulo,SP: Abril, 1978. (Coleção Os pensadores).

QUINE, W.V. O Alcance da linguagem da Ciência. In: . Filosofia e linguagem. Tradução de João Sàágua e Rui K. Silva. Lisboa: Asa, 1995.

Revista de Filosofia, Curitiba, v. 17 n.20, p. 125-136, jan./jun. 2005. 
. Cinco marcos do empirismo. In:

. Filosofia e lingua-

gem. Tradução de João Sàágua e Rui K. Silva. Lisboa: Asa, 1995.

. Dois dogmas do empirismo. In:

De um ponto de

vista lógico: Tradução de Marcelo G.S. Lima. Sã̃o Paulo,SP:Abril, 1980. (Coleção Os Pensadores).

. Epistemologia naturalizada. In:

. Relatividade ontológi-

ca e outros ensaios. Tradução de Andréa Loparic. São Paulo,SP:Abril, 1980. (Coleção Os Pensadores).

. Notas sobre uma teoria da referência. In:

Filosofia e

linguagem. Tradução de João Sàágua e Rui K. Silva. Lisboa: Asa, 1995.

A Relatividade ontológica. In:

Relatividade ontoló-

gica e outros ensaios. Tradução de Oswaldo Porchat. São Paulo,SP: Abril, 1980. (Coleção Os Pensadores).

. Le mythe de la signification (1958/59). Paris: Colloque de Royamont, 1960.

VIDAL, V. Contribuições do sistema filosófico de Quine para as investigações da filosofia analítica. In: CARVALHO, Maria Cecília (org.). Paradigmas filosóficos da atualidade. Papirus, Campinas, 1989.

Recebido em: Received in: 11/02/2005 Aprovado em: Approved in: 25/03/2005 